\title{
ACIDENTES DE TRÂNSITO EM JATAÍ (GO): UMA ANÁLISE DE PERÍODO DE 2013 A 2015
}

\author{
Traffic accidents in Jataí (GO): na analysis oh the period from 2013 to 2015 \\ Juliana Freitas Silva* \\ Maria José Rodrigues **

\begin{abstract}
* Mestranda no PPG em Geografia - UFG Regional Jataí - jufreitassilva@yahoo.com.br. ** Docente do PPG em Geografia - UFG Regional Jataí - mariarodriguesgeo@gmail.com.
\end{abstract}

Recebido em 08/05/2018. Aceito para publicação em 25/06/2018.

Versão online publicada em 10/08/2018 (http://seer.ufrgs.br/paraonde)

\begin{abstract}
Resumo: Os acidentes de trânsito são agravos que não escolhem classe social, raça, gênero e nem faixa etária. Essa perturbação está presente em todas as cidades, porém em diferentes escalas, inclusive na cidade de Jataí, localizada no Sudoeste Goiano. Assim, com o objetivo de conhecer as características dos acidentes ocorridos na cidade de Jataí no período de 2013 a 2015, o presente estudo se utilizou de dados cedidos pelo setor de estatística da Superintendência Municipal de Trânsito e o Departamento de Informática do Sistema Único de Saúde (DATASUS). Os acidentes de trânsito em Jataí para o período analisado têm maior ocorrência aos sábados e no período vespertino. Pessoas do gênero masculino e com idade entre 31 a 40 anos são os que mais se envolvem nesses acidentes. Esses dados corroboram com as médias de outras cidades brasileiras.
\end{abstract}

Palavras-chave: Acidentes de trânsito, análise, Jataí.

\begin{abstract}
Traffic accidents are grievances and it doesn't choose social class, race, gender or age group. This disturbance is present in all cities, but in different scales, including in the city of Jataí, located in the Goiás Southwest. Thus, with the objective of to know the characteristics of the accidents occurred in the city of Jataí in the period between 2013 and 2015,the present study was based on data provided by the Municipal Superintendence of Traffic and the Department of Information Technology of the Health (DITH). The traffic accidents in Jataí, for the period analyzed, have a higher occurrence on Saturdays and in the afternoon period. Men who are between 31 and 40 years of age are those most involved in these accidents. These data corroborate with the averages of other Brazilian cities.
\end{abstract}

Key-words: Traffic accidents, analysis, Jataí.

\section{Introdução}

Os acidentes de trânsito é uma das principais causas de morte em todas as faixas etárias em todo mundo. Embora acidentes aéreos causem um maior temor na população, pois matam uma grande quantidade de pessoas por vez de ocorrência, os acidentes terrestres têm um maior impacto na vida das pessoas, em decorrência dos estragos físicos e mentais que eles causam e da quantidade em que ocorrem.

Na cidade de Jataí - Goiás (G0), município de residência das pesquisadoras, frequentemente são noticiados casos de acidentes de trânsito e alguns deles são de alta gravidade o que despertou o interesse pela temática.

O município de Jataí começou a se destacar nacionalmente devido ao advento da Revolução Verde e de políticas de incentivo a ocupação dos cerrados brasileiros para fins de desenvolvimento da agricultura. Esse período foi marcado pela mecanização do campo e consequentemente ampliou a migração das pessoas para as cidades. Tal migração alterou a relação campo-cidade, o que gerou 
grande impacto na área urbana do município, causando por sua vez alguns problemas como falta de moradia, segregação socioespacial e violências.

Dentre as violências, temos a violência sexual, doméstica, violência no trânsito, entre outros tipos. 0 nosso objeto de estudo será a violência no trânsito causada em decorrência dos acidentes. Alguns autores, como Silva (2007), Bonito (2011), Chagas (2011) e Morais (2013), que trabalham com acidentes de trânsito, relatam que as dificuldades para se realizar trabalhos sobre os acidentes de trânsito se referem as fontes de pesquisa, pois a maioria se utiliza de informações obtidas através de boletins de ocorrência e estes apresentam algumas inconsistências nas informações e campos sem preenchimento.

Embora seja um tema de grande interesse, são escassos os trabalhos disponíveis, principalmente para o município de Jataí, se limitando a levantamentos para fins de divulgação por parte da Secretaria Municipal de Saúde (SMS) e da Superintendência Municipal de Trânsito (SMT).

Assim com vistas a identificar as características desses acidentes e se estes acompanham as estatísticas nacionais, este trabalho teve por objetivo caracterizar os acidentes de trânsito ocorridos na cidade de Jataí (GO) no período de 2013 a 2015 para traçar o perfil desses acontecimentos.

\section{Desenvolvimento}

Jataí é um município do interior do Estado de Goiás, localizada a 320,2 Km da capital Goiânia e $528,7 \mathrm{Km}$ do Distrito Federal. Fundada no final do século XIX, surgiu como fruto da busca por novas áreas de expansão agropecuária vindo a se tornar um grande pólo agroindustrial. De acordo com o Instituto Brasileiro de Geografia e Estatística - IBGE (2017), a população estimada de Jataí em 2016 era de 97.077 pessoas, sendo que, de acordo com o último censo de 2010, Jataí contava com uma população de 88.006 pessoas, sendo que destes, 81.010 se encontravam na zona urbana e 6.996 na zona rural, distribuídos em uma área territorial de $7174.220 \mathrm{~km}^{2}$, cuja densidade demográfica era de $12.27 \mathrm{hab} / \mathrm{km}^{2}$. Na Figura 1 apresentamos a localização da área de estudo.

As mudanças que ocorreram no cenário de Jataí aconteceram em parte graças à chamada Revolução Verde ocorrida na década de 1970, que tinha como promessa a modernização do campo através do incentivo à aquisição de material tecnológico.

A modernização do campo alterou não somente o meio rural, mas também o urbano, pois as comunidades rurais, em grande parte, migraram para as cidades levando com elas seus costumes, tradições, crenças e modo de vida, passando pelo processo de perca de suas identidades. Essa inserção da agricultura capitalista no estado de Goiás, principalmente nas áreas de cerrado, alterou de forma significativa a configuração socioespacial do território goiano. As cidades passaram a ser lócus principal desta ocupação e a antiga paisagem do cerrado foi se modificando e se transformando, predominantemente, em grandes plantações e em empresas agropecuárias.

As migrações se tornaram mais frequentes devido a programas governamentais que estimulavam a colonização agrícola. Para o cerrado brasileiro, três projetos foram implantados segundo Santos (2010): o Programa de Assentamento Dirigido do Alto Paranaíba (PADAP), o Programa de Desenvolvimento dos Cerrados (POLOCENTRO) e o Programa de Cooperação Nipo-Brasileiro para o Desenvolvimento dos Cerrados (PRODECER).

Esse intenso processo de urbanização, promovido em parte por essas migrações, traz uma série de problemas, como a falta de moradia, transporte, educação, saúde e a crescente poluição ambiental, o que faz deteriorar a qualidade de vida das pessoas. Um desses problemas, que é o objeto de estudo deste trabalho é a violência no trânsito em decorrência dos acidentes de trânsito. 


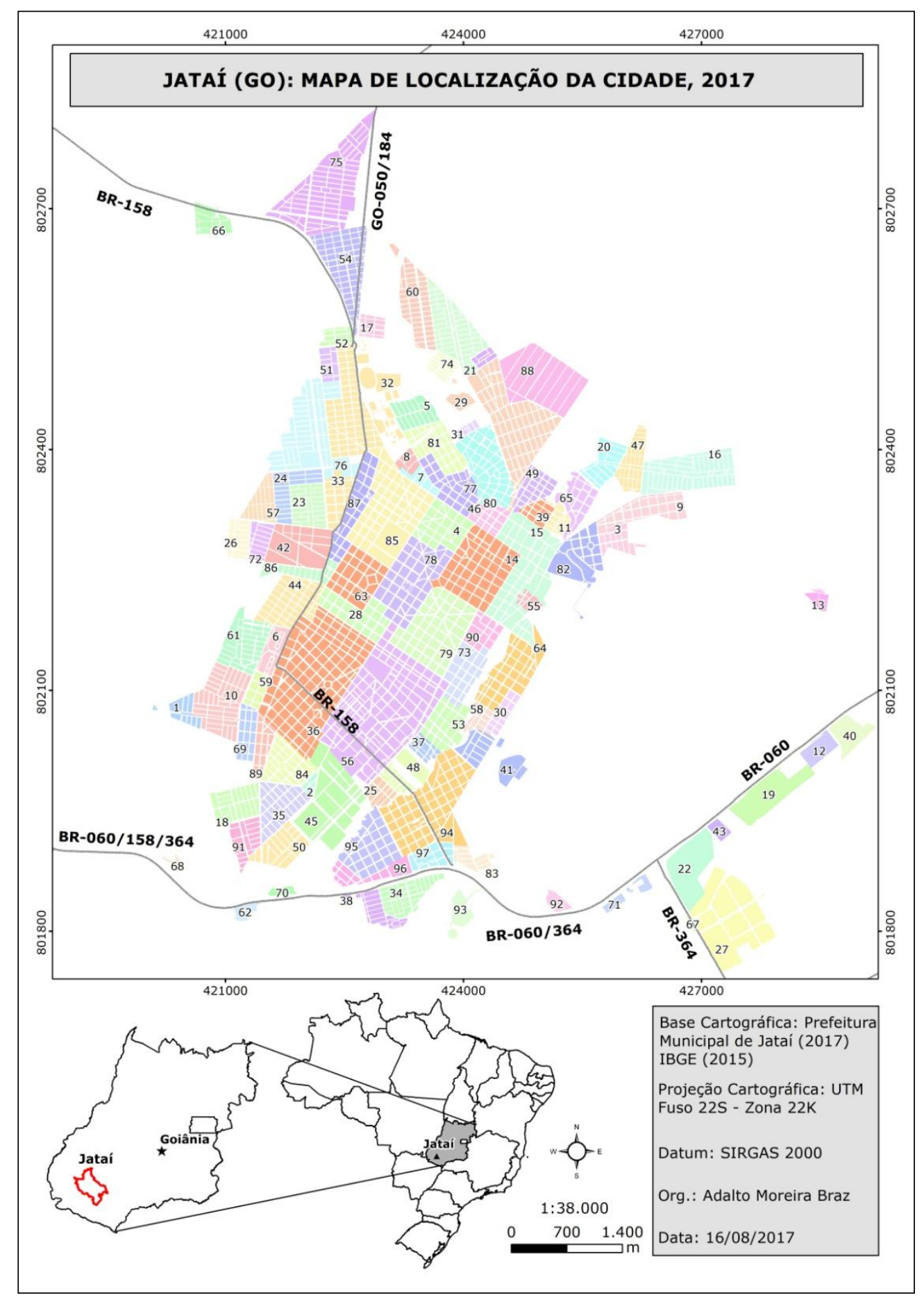

Figura 1 - Jataí (G0): localização e perímetro urbano da área de estudo, 2017

De acordo com França (1979), o automóvel chegou a Jataí no ano de 1918, este se misturou aos elementos já presentes na paisagem, como as tropas e as boiadas. A chegada do automóvel, de acordo com Melo (2003), possibilitou uma maior fluidez, mercadorias e informações, se comparado com o transporte que era realizado por animais.

O cenário mudou e para o ano de 2015 a estimativa de frota de veículos em Jataí era de 67.846 (IBGE, 2017). Aumenta-se a quantidade de veículos, porém a infraestrutura da cidade por vezes não acompanha esse crescimento. A Avenida Goiás em 1945 era uma rua que recebia carros de bois e apenas alguns veículos, hoje passam centenas de veículos de todos os tipos, além dos pedestres. 0 
tempo passou, os veículos aumentaram, mas poucas mudanças ocorreram nas vias para acompanhar essas alterações.

Tal problemática gera problemas de mobilidade urbana o que já foi objeto de estudo, devido à importância do tema. Camara (2013) ao analisar a questão da mobilidade urbana na parte central de Jataí, com foco na Avenida Goiás, uma das principais vias da cidade, verificou muitos pontos em desacordo com a legislação vigente e coletou várias reclamações de usuários sobre o trânsito e a falta de estacionamento para os veículos.

Quanto aos acidentes de trânsito, um levantamento do Núcleo de Vigilância Epidemiológica e Ambiental em Saúde de Jataí para o período de 2009 a 2011, destacou que a partir da implantação das fichas de notificação, ocorrida no fim de 2009, a cada ano mais acidentes eram registrados (Boletim, 2012). Mostrando a importância de estudos sobre essa temática.

\section{Procedimentos Metodológicos}

0 presente estudo é uma análise exploratória dos dados de acidentes de trânsito ocorridos no município de Jataí, no período de 2013 a 2015. Os dados apresentados são resultados parciais da pesquisa intitulada "Violência no trânsito: espacialização dos acidentes envolvendo motociclistas no período de 2013 a 2015, na cidade de Jataí (GO)", como requisito parcial para obtenção do título de mestre em Geografia pela Universidade Federal de Goiás - Regional Jataí.

Os dados utilizados para estruturação deste trabalho foram disponibilizados pela Superintendência Municipal de Trânsito para o período analisado. Estes estão organizados em um relatório denominado relatório geral, o qual está categorizado em quantitativo de ocorrências por ano, por dia da semana, período do dia, tipo de vítima/acidentes, natureza do acidente, tipo de veículo, tipos de controle de tráfego encontrados, sexo do condutor, faixa etária do condutor, categorias de Carteira Nacional de Habilitação, uso de acessórios e equipamentos de proteção individual e perfil da vítima.

A variável quantidade de óbitos foi obtida no site do Departamento de Informática do SUS (DATASUS) para os anos de 2013 e 2014 e disponibilizados pelo Núcleo de Vigilância Epidemiológica e Ambiental em Saúde para o ano de 2015.

\section{Resultados e discussão}

A partir da análise dos dados, foram contabilizados 1100 acidentes em 2013, 1261 em 2014 e 322 em 2015. Essa redução do registro de acidentes de 2014 para 2015 pode ser justificada, pois a partir do ano de 2015, o 15으 Batalhão da Polícia Militar passou a se deslocar para a área dos acidentes somente para ocorrências com vítimas, com isso, houve uma redução no número de boletins preenchidos. A partir desse ano, os acidentes que não apresentavam vítimas, passaram a ser registrados online em site específico para tal procedimento. Essa mudança de atuação já havia ocorrido em outras cidades de Goiás e em outros estados, sendo que em sua maioria esta alteração se deu por conta do baixo quadro efetivo de servidores e o tempo que estes despendiam para atendimento a essas ocorrências, impossibilitando o deslocamento para ocorrências consideradas de maior relevância para o serviço policial.

De acordo com dados obtidos no Departamento de Informática do Sistema Único de Saúde DATASUS, Jataí apresentou 35 óbitos em 2013; 36 óbitos em 2014 e 39 óbitos em 2015, ou seja, ao longo dos anos no período de estudo, a quantidade de acidentes diminuiu consideravelmente, por conta da mudança na ação policial, porém os óbitos aumentaram. Este fato deve ser levado em consideração no momento da estruturação de ações voltadas para a diminuição dos acidentes e não somente através da verificação da quantidade de acidentes registrados. 
No relatório geral gerado pelo SMT esse número para 2013 e 2014 é de cinco mortos e para 2015 de 04 mortos. Essa diferença pode ser explicada, pois nos boletins consta o quantitativo de mortos no local e nem sempre a Polícia tem o retorno do estado da vítima após entrada no hospital. Queiroz (2003) apresenta em seu estudo que a maioria das vítimas de acidentes não falece no local, chegando a $38,3 \%$ as pessoas que morrem no local e $98,3 \%$ que morrem em até 30 dias - porcentagem acumulada.

Essa e outras variações encontradas em estudos que trabalham com essa temática justificam a necessidade de um boletim unificado, pois isso evitaria além de subnotificações, a presença de dados duplicados nos diferentes documentos. A unificação propiciaria informações mais confiáveis e poderia assim servir de subsídio para ações mais eficazes com vistas a redução do número de acidentes.

Com a análise dos dados, verificamos que a maioria desses acidentes ocorreram aos sábados para todos os anos, seguido de sexta-feira para os anos de 2013 (182) e 2014 (198) e segunda-feira para o ano de 2015 (49), como pode ser verificado na Tabela 1.

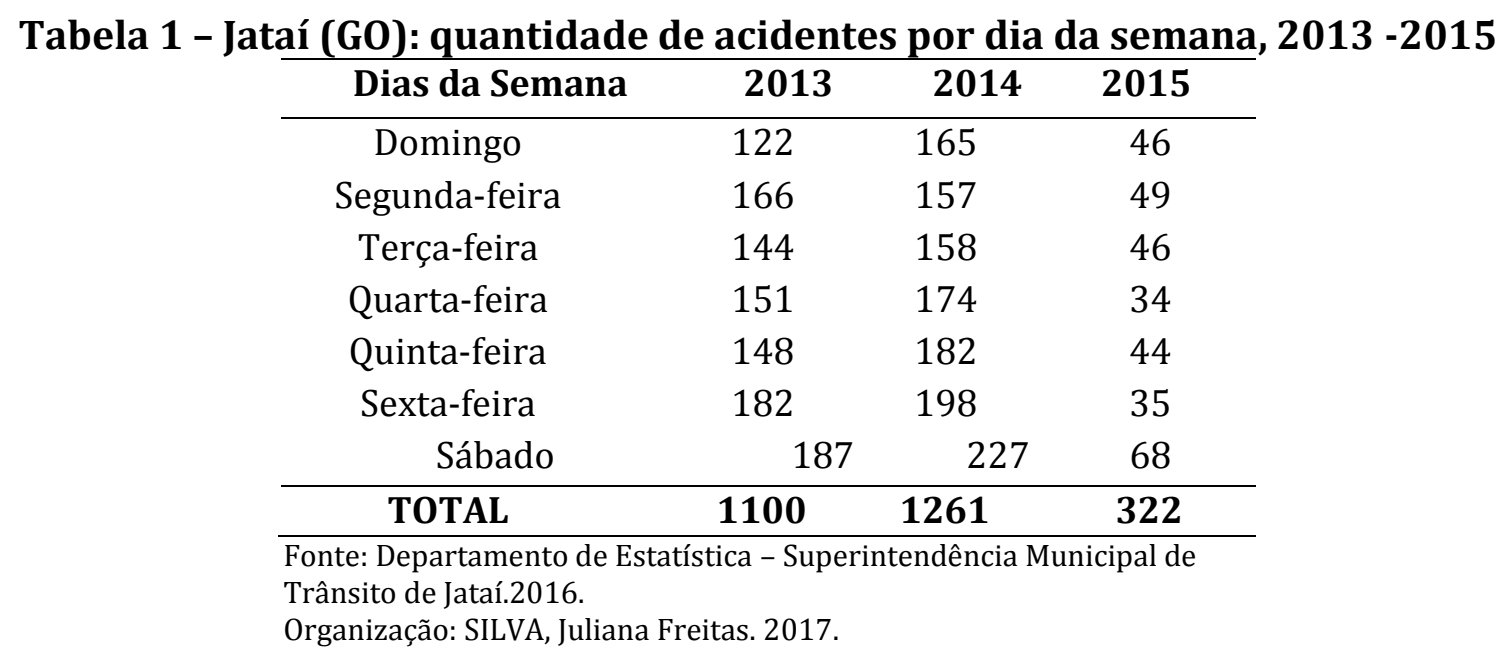

No sábado, geralmente um dia em que as pessoas se encontram em período de folga, as altas velocidades e um menor fluxo de veículos nas vias, são fatores que podem propiciar a ocorrência de acidentes.

Bernardino (2007) ao analisar os dados dos acidentes de trânsito da cidade de Uberlândia - MG no período de 2000 a 2004 apresentou que nos dias de sexta- feira e sábado ocorreram mais acidentes do que os demais dias. Associado a isso, a autora traz que tal prevalência de acidentes nestes dias pode se justificar pelo período de descontração, momento em que as pessoas buscam se divertir deixando os compromissos e responsabilidades de lado e unindo bebidas a direção.

Se por um lado, um menor fluxo de veículos pode ocasionar acidentes, por conta das altas velocidades, a situação contrária também pode causar acidentes, pois conforme apresentado no Gráfico 1, no período vespertino ocorreram mais acidentes e geralmente nesse período, o fluxo de veículos é maior, principalmente próximo a agências bancárias, supermercados e escolas. Em 2013 o período que mais apresentou acidentes seguido do vespertino, foi o matutino e nos anos de 2014 e 2015 o período noturno. 


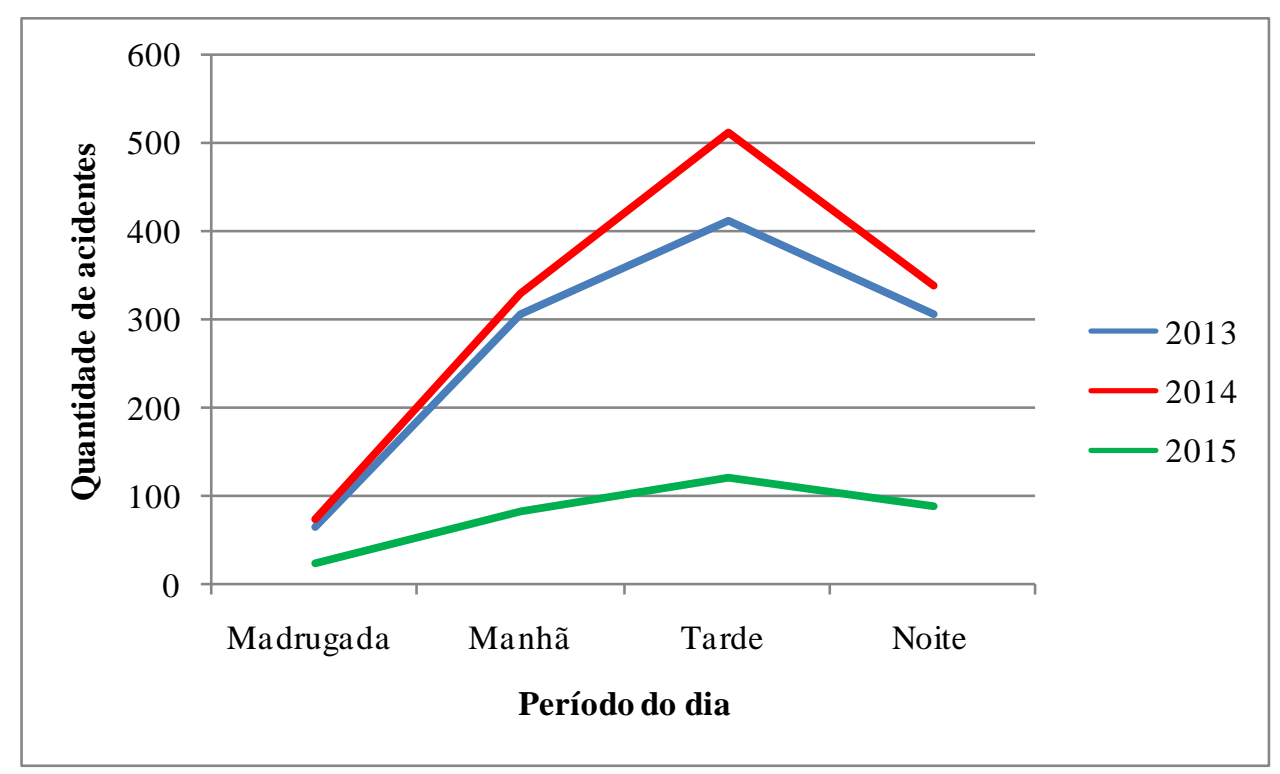

Gráfico 1 - Jataí (G0): quantidade de acidentes por período do dia, 2013 - 2015

Fonte: Departamento de Estatística - Superintendência Municipal de Trânsito de Jataí.2016.

Organização: SILVA, Juliana Freitas. 2017.

Os locais que atraem as pessoas, como as escolas, bancos, supermercados, segundo Rezende (2010) podem ser chamados de pólos geradores de tráfego, pois são empreendimentos que atraem grande quantitativo de pessoas e consequentemente aumenta o fluxo de veículos, sejam eles de qualquer tipo. Esse aumento por sua vez pode ocasionar acidentes.

Estudos em locais considerados pólos geradores de tráfego poderiam auxiliar em ações de planejamento urbano para correções no espaço urbano. Associado a isso, Chagas (2011) propõe o estudo dos fatores contribuintes de acidentes de trânsito urbanos. Esses fatores que geralmente estão relacionados a três grupos principais, fator humano, fator veicular e fator viário-ambiental poderiam identificar as reais causas dos acidentes e com isso facilitar na estruturação de medidas pontuais nas cidades.

Geralmente os acidentes ocorrem com a associação de dois ou mais fatores, porém somente com dados provenientes dos boletins se torna mais difícil a identificação desses fatores.

0 tipo mais comum de acidente é o abalroamento entre veículos, no período analisado este tipo de acidente esteve presente em $56,59 \%$ das ocorrências totais no período analisado, seguido por colisão $(17,07 \%)$ e choque em objeto fixo $(9,81 \%)$ - Tabela 2.

Tabela 2 - Jataí (G0): natureza dos acidentes de trânsito, 2013 - 2015.

\begin{tabular}{lccc}
\hline Natureza do acidente & $\mathbf{2 0 1 3}$ & $\mathbf{2 0 1 4}$ & $\mathbf{2 0 1 5}$ \\
\hline Abalroamento & 686 & 620 & 119 \\
Colisão & 196 & 211 & 23 \\
Choque em objeto fixo & 138 & 91 & 18 \\
Capotamento & 11 & 7 & 4 \\
Tombamento & 8 & 2 & 0 \\
Atropelamento & 31 & 26 & 7 \\
Atropelamento de animal & 2 & 1 & 0 \\
Outros & 17 & 295 & 5 \\
TOTAL & $\mathbf{1 0 8 9}$ & $\mathbf{1 2 5 3}$ & $\mathbf{1 7 6}$ \\
\hline
\end{tabular}

Fonte: Departamento de Estatística - Superintendência Municipal de Trânsito de Jataí.2016. Organização: SILVA, Juliana Freitas. 2017. 
De acordo com o IBGE (2017), para o período analisado Jataí apresentava uma frota de 61.058 veículos em 2013; 65.110 em 2014 e 67.846 em 2015 (Tabela 3). Destes a maioria, cerca de 41\% são automóveis, o que em parte poderia justificar a grande quantidade de acidentes envolvendo esse tipo de veículo (Tabela 4).

Tabela 3 - Jataí (G0): frota do município de Jataí, 2013 - 2015

\begin{tabular}{lccc}
\hline Tipo de veículo & $\mathbf{2 0 1 3}$ & $\mathbf{2 0 1 4}$ & $\mathbf{2 0 1 5}$ \\
\hline Automóvel & 25.041 & 26.783 & 27.847 \\
Caminhão & 2.180 & 2.282 & 2.337 \\
Caminhão trator & 669 & 731 & 777 \\
Caminhonete & 7.083 & 7.684 & 7.981 \\
Camioneta & 1.129 & 1.260 & 1.336 \\
Micro-ônibus & 127 & 133 & 148 \\
Motocicleta & 14.218 & 14.774 & 15.172 \\
Motoneta & 7.294 & 7.728 & 8.087 \\
Ônibus & 220 & 236 & 267 \\
Trator de rodas & 0 & 0 & 0 \\
Utilitário & 295 & 364 & 422 \\
Outros & 2.802 & 3.135 & 3.472 \\
\hline Total & $\mathbf{6 1 . 0 5 8}$ & $\mathbf{6 5 . 1 1 0}$ & $\mathbf{6 7 . 8 4 6}$ \\
\hline Fonte: IBGE (2017). & & \\
Organização: SILVA, Juliana Freitas. 2017. &
\end{tabular}

Tabela 4 - Jataí (GO): quantidade de veículos envolvidos por tipo, 2013 - 2015

\begin{tabular}{cccc}
\hline Tipo de veículo & $\mathbf{2 0 1 3}$ & $\mathbf{2 0 1 4}$ & $\mathbf{2 0 1 5}$ \\
\hline Automóvel ou Caminhoneta (Exceto Táxi) & 1172 & 1393 & 151 \\
Motocicleta ou Motoneta & 477 & 669 & 116 \\
Caminhão & 133 & 95 & 4 \\
Ciclomotor & 28 & 72 & 6 \\
Ônibus ou micro-ônibus & 38 & 35 & 3 \\
Bicicleta & 17 & 12 & 1 \\
Moto taxi & 1 & 2 & - \\
Pedestre & 8 & 6 & - \\
Taxi & 2 & 1 & 1 \\
Outros & 31 & 10 & 1 \\
\hline Total & $\mathbf{1 9 0 7}$ & $\mathbf{2 2 9 5}$ & $\mathbf{2 8 3}$ \\
\hline
\end{tabular}

Fonte: Departamento de Estatística - Superintendência Municipal de Trânsito de Jataí.2016. Organização: SILVA, Juliana Freitas. 2017

Em segundo lugar temos que acidentes com envolvimento de motocicletas ou motonetas. A categoria de usuários que utilizam esse tipo de veículo já foi objeto de estudo de vários autores. Essa preocupação em parte se dá por ser essa categoria considerada vulnerável devido à sua estrutura do veículo. Diante disso é necessário que as medidas de políticas públicas se voltem para essa categoria, porém o que percebemos é o maior incentivo para compra desses veículos através de facilidades de crédito e de legislação mais branda para veículos com até 50 cilindradas.

Com isso e aliado ao baixo consumo desses veículos, a necessidade de se deslocar em um menor tempo devido ao aumento das distâncias, os usuários optam cada vez mais por este veículo 
individual.

Ao analisar as categorias relacionadas ao perfil do condutor, verificamos que a maioria dos condutores envolvidos nos acidentes são do gênero masculino (3.464) conforme demonstrado no Gráfico 2 e a faixa etária de maior envolvimento é dos 31 aos 40 anos (Gráfico 3).

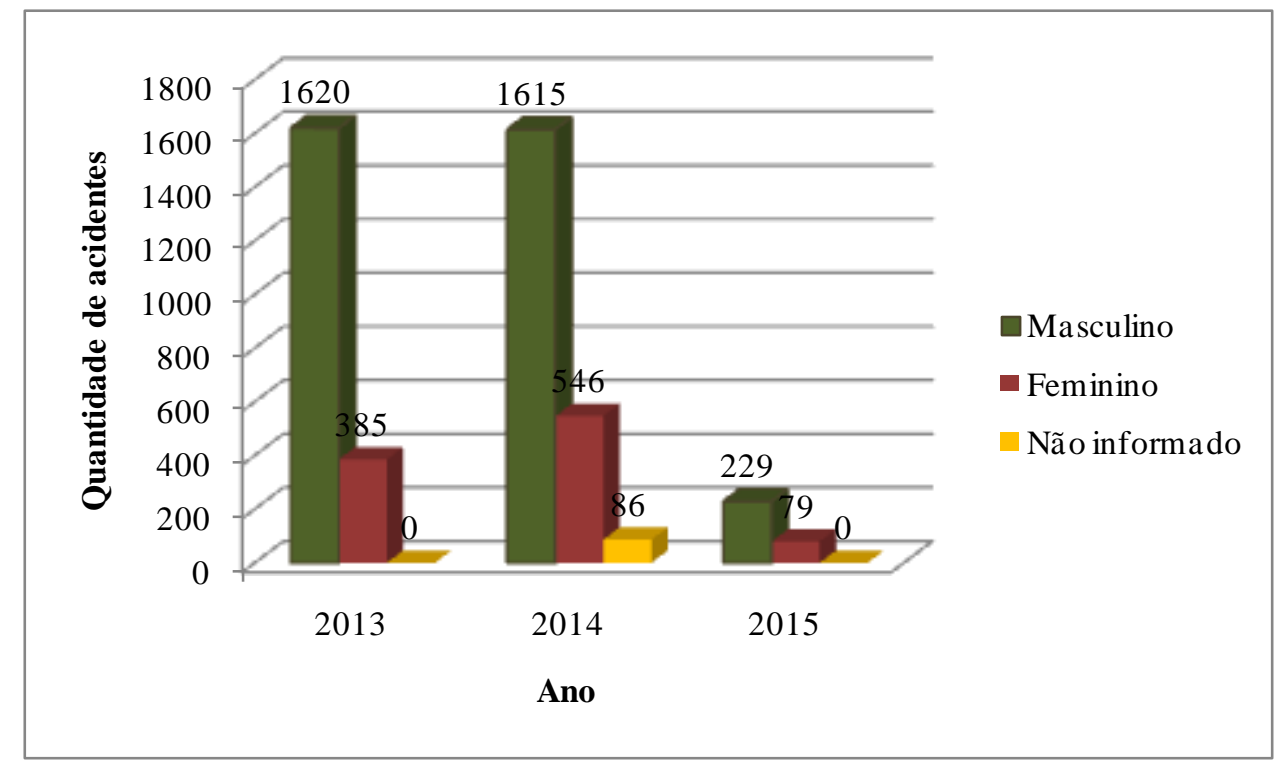

Gráfico 2 - Jataí (G0): quantidade de acidentes por sexo do condutor, 2013 - 2015

Fonte: Departamento de Estatística - Superintendência Municipal de Trânsito de Jataí.2016.

Organização: SILVA, Juliana Freitas. 2017.

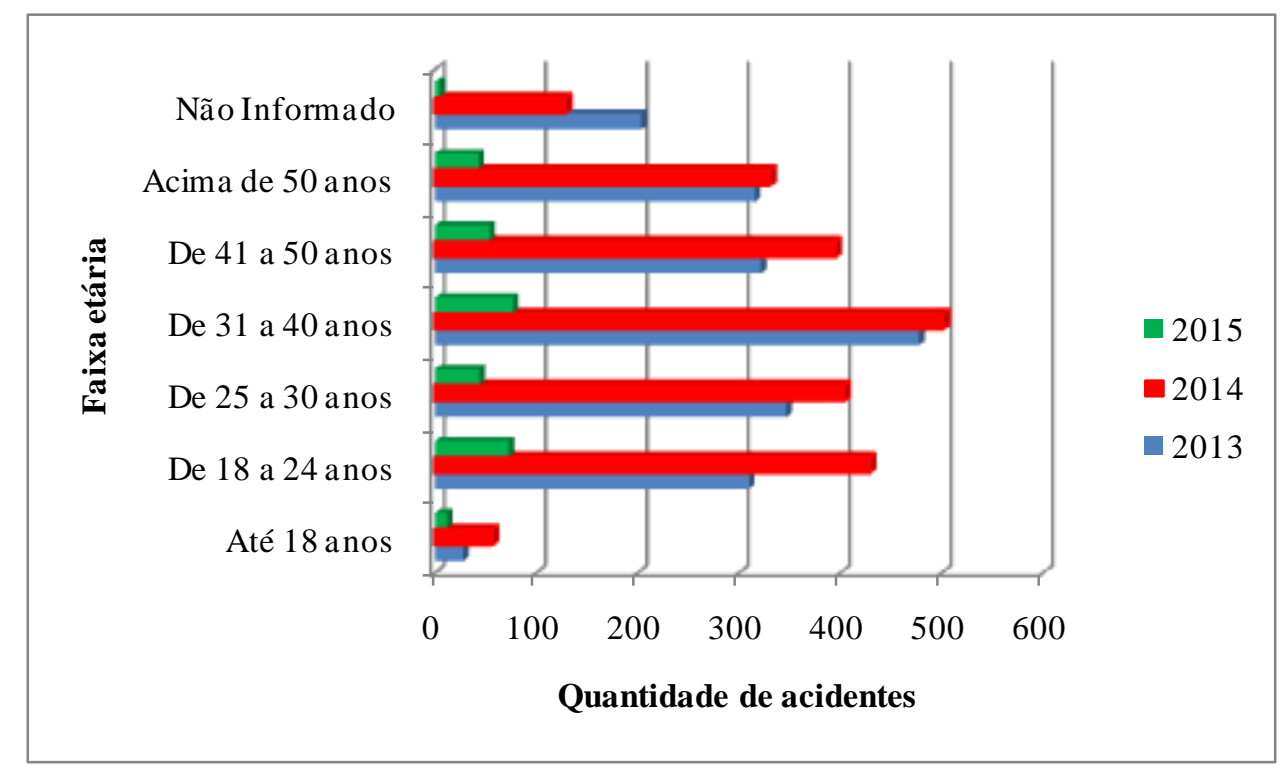

Gráfico 3 - Jataí (G0): quantidade de acidentes por faixa etária do condutor, 2013 - 2015

Fonte: Departamento de Estatística - Superintendência Municipal de Trânsito de Jataí.2016.

Organização: SILVA, Juliana Freitas. 2017.

Segundo a Organização Mundial de Saúde (2015), do total de mortes no trânsito, a faixa etária dos 15 a 44 anos corresponde a 59\% dos casos em todo o planeta. Waiselfisz (2013, p.05) complementa que "os acidentes de trânsito representam a terceira causa de mortes na faixa etária de 30 a 44 anos", mesma faixa onde verificamos maior número de ocorrências para o município de Jataí. 


\section{Considerações Finais}

Mesmo diante da mudança de metodologia quanto ao deslocamento da polícia militar ao atendimento das ocorrências, após a análise dos dados, verificamos que Jataí possui características semelhantes a outras cidades brasileiras. Um fato preocupante diz respeito ao quantitativo de óbitos em decorrência desses acidentes, pois ao longo desses três anos, esse número aumentou, inferindo que tal fato deve ser melhor avaliado pelos gestores.

Ao verificarmos características quanto ao perfil do condutor, percebemos que a grande maioria, $23,18 \%$ tem acidentes com o envolvimento de pessoas na faixa dos 31 a 40 anos, seguidos de 17,81\% na faixa entre 18 a 24 anos e de pessoas entre 25 a 30 anos, perfazendo $17,43 \%$ do total. Nessas faixas se enquadram a maioria da população ativa da cidade, o que pode ocasionar em absenteísmo nos postos de trabalhos e consequentemente gerar indenizações.

Ainda nesse viés, $76 \%$ dos acidentes ocorridos no período de análise ocorreram com pessoas no gênero masculino. Esse quantitativo, para lares que em sua maioria ainda são mantidos pelos patriarcas, pode trazer consequências sérias para esses lares.

Ao se considerar as variáveis que envolvem os acidentes de trânsito, percebemos quão vasto e importante são estudos relacionados a essa temática no âmbito da ciência geográfica.

\section{Referências}

BERNARDINO, A. R. Espacialização dos acidentes de trânsito em Uberlândia (MG): técnicas de geoprocessamento como instrumento de análise - 2000 a 2004. 2007. Tese (Doutorado em Geografia Humana) - Faculdade de Filosofia, Letras e Ciências Humanas, Universidade de São Paulo, São Paulo, 2007. Disponível em:<http://www.teses.usp.br/teses/disponiveis/8/8136/tde-13072007113618/> Acesso em: 25 de ago. 2016.

BONITO, Rosuíta Fratari. Riscos de acidentes e mortes em usuários de motocicletas em Uberlândia MG. 2011. Tese (doutorado) - Universidade Federal de Uberlândia, Programa de Pós-Graduação em Geografia, Uberlândia, 2011.

CAMARA, Michaela Andréa Bette. Mobilidade urbana e acessibilidade em Jataí-GO: em busca do efetivo exercício do direito à cidade, 2013. Dissertação (Mestrado) - Universidade Federal de Goiás, Programa de Pós-Graduação em Geografia, 2013.

CHAGAS, Denise Martins. Estudos Sobre Fatores Contribuintes de acidentes de trânsito urbano. Dissertação (Pós-Graduação em Engenharia de Produção) - Universidade Federal do Rio Grande do Sul -UFRGS. Rio Grande do Sul, $2011 . \quad$ Disponível em:<http://www.lume.ufrgs.br/bitstream/handle/10183/32553/000786219.pdf?sequence=1>. Acesso em: 13 jan 2017.

FRANÇA, Basileu Toledo. Cavalo de Rodas. Goiânia: Oriente, 1979.

IBGE - Instituto Brasileiro de Geografia e estatística. Cidades. Disponível em<http://cidades.ibge.gov.br/xtras/home.php> . Acesso em 19 abr 2017.

INFORMATIVO. Boletim Epidemiológico 01/2012 - Secretaria Municipal de Saúde de Jataí - Disponível em:

<http://www.jatai.go.gov.br/index.php?option=com_content\&view=article\&id=7108\&Itemid=4 29> Acesso em 15 jan 2017.

MELO. Nagela Aparecida de. Interação Campo-Cidade: a (re)organização sócio espacial de Jataí (GO) no período de 1970 a 2000. 2003. 179f. Dissertação (Mestrado em Geografia) Universidade Federal 
de Uberlândia, Uberlândia, 2003.

MORAIS, S. D. Q. de. Acidentes de trânsito com motociclistas: um estudo social e participativo. Dissertação (mestrado) - Universidade Federal de Uberlândia, Programa de Pós-Graduação em Geografia, 2013.

OMS. 10 facts on global road safety, 2015.2 Disponível em:<http://www.who.int/features/factfiles/roadsafety/en/ >. Acesso em 03 fev 2017.

QUEIROZ, M. P. Análise Espacial dos Acidentes de Trânsito do Município de Fortaleza. 2003. 124 fl. (Dissertação) Programa de Mestrado em Engenharia de Transportes, Universidade Federal do Ceará, Fortaleza, 2003.

RESENDE, L. de. Conflitos de trânsito em áreas de polos geradores de tráfego e instituições de interesse social: a educação para o trânsito como alternativa. 2010. 249 fl. (Dissertação) Programa de PósGraduação em Geografia da Universidade Federal de Uberlândia, Uberlândia, 2010. Disponível em: <http://www.ppgeo.ig.ufu.br/node/138> Acesso em 26 ago 2016.

SANTOS, Mauro Augusto dos. A influência da dinâmica demográfica e domiciliar no processo de ocupação do Cerrado Brasileiro: o caso do Programa de Assentamento Dirigido do Alto Paranaíba, Minas Gerais, Brasil (Tese-doutorado). Faculdade de Ciências Econômicas da Universidade Federal de Minas Gerais, 2010.

SILVA, R. M. Acidentes de trânsito com envolvimento de motociclistas: Uberlândia - 2002 a 2004. Dissertação (Mestrado) - Universidade Federal de Uberlândia - Programa de Pós-Graduação em Geografia, 2004.

WAISELFISZ, J. J. Mapa da Violência 2013. Acidentes de Trânsito e Motocicletas. São Paulo: Instituto Sangari, 2013. Disponível

em:<http://www.mapadaviolencia.org.br/pdf2013/mapa2013_transito.pdf $>$.Acesso $\quad$ em: 14 nov.2015. 